\title{
AC 2007-2741: PROGRAM OUTCOME ASSESSMENT IN AN INDUSTRIALLY SPONSORED SENIOR CAPSTONE COURSE
}

\section{Nirmala Gnanapragasam, Seattle University}

Nirmala Gnanapragasam is an Associate Professor in the Department of Civil and Environmental Engineering at Seattle University. She is a geotechnical engineer and is a registered Professional Engineer in the State of Washington. She is the design coordinator of the senior capstone design program in the Civil and Environmental Engineering department, is active in consulting, in engineering education research, and in professional organizations. 


\title{
Program Outcome Assessment in an Industrially Sponsored Senior Capstone Course
}

\begin{abstract}
ABET 2000 program criteria requires that student participate in a major design experience prior to graduation (criterion 4) and that programs demonstrate, using primarily direct measures of student performance, that all graduates have achieved the a-k program outcomes (criterion 3). The civil engineering capstone design program at Seattle University has developed, implemented and improved various assessment tools over the past several years to assess each of the a-k program outcomes. All constituents participated in the assessment process. The paper provides examples of the various assessment tools, discusses their effectiveness and how the feedback of the assessment is fed back to the students to keep them in the assessment loop. These assessments satisfied a-k program outcomes, benefited the students and provided valuable information to improve the program. The engineering program had a successful ABET visit in 2005.
\end{abstract}

\section{Introduction}

Criterion 4 of ABET 2000 requires that students participate in a major design experience prior to graduation. Project based senior capstone courses satisfy this criterion very well. These senior design projects also have the added advantage of being a great venue to demonstrate the ABET Engineering criterion 3 (a-k) program outcomes.

The purpose of this paper is to describe the development and implementation of the assessments tools that satisfy criterion $3(\mathrm{a}-\mathrm{k})$ program outcomes and the course learning outcomes developed by the Civil Engineering Department at Seattle University. The paper briefly describes the senior design program, defines the assessment tools, shows how the various constituents were incorporated into the assessment process, and discusses some of the results of the assessment. The paper summarizes the benefits of having assessment tools in place and how they are improved continuously to improve the overall program.

\section{Setup of Senior Design Program at Seattle University}

Seattle University has had an industrially sponsored senior design program within the College of Science and Engineering for the past 20 years. The 'Project Center', an entity within the College of Science and Engineering, manages the administrative aspect of all projects. Design projects that could be completed within an academic-year are recruited from local industries by the Project Center personnel and the department's design coordinator (ie. the instructor of the senior design sequence) in summer and early fall prior to the beginning of the academic year. Teams of three to four students work under the direction of a company liaison and a faculty advisor to solve a real life engineering problem. 
Teams spend the fall quarter meeting with the sponsoring company liaison(s) and the faculty advisor, visiting the project site (if applicable), understanding the overall goal of the project, brainstorming ideas for solving the problem, and defining the scope and final project deliverables. Teams make several presentations to the class through out the quarter and a presentation to the sponsoring companies at the end of the quarter. They also submit a written proposal to the department and to the sponsors.

The winter and spring quarters are spent doing the actual work on the project. The project culminates in spring with a written project report, a presentation at the sponsor's office, an oral and poster presentation open to the campus and local community on 'projects day' which is a mini-conference style event.

Throughout the year, all team members meet with their faculty advisor once a week and with their sponsor liaison biweekly. Each student within a team serves as a Project Manager for part of the academic year. The Project Manager is in charge of running the project meetings, assigning tasks to team members at the meetings and following up with action items, and communicating with the liaison and the faculty advisor.

The year-long capstone experience provides the students ample opportunity to integrate their knowledge of science, engineering, ethics and humanities with creative problem solving, to work effectively in a team setting, to improve communication skills, to understand and respond to client needs, and to develop project management and human relations' skills. Because the senior design project covers many of the topics in ABET criterion 3 (a-k) program outcomes, the Civil and Engineering department at Seattle University has developed and implemented several assessment tools over the past several years. These assessment tools are continuously improved with the input from internal and external constituents of the program.

\section{Involvement of Constituents in the Assessment Process}

Internal and external constituents of the civil engineering program take part in the various assessment processes. The internal constituents are the faculty and academic staff, Project Center personnel and students. The primary external constituents include project sponsor liaisons, civil engineering department advisory board, and project center advisory board. Some of the above constituents are self explanatory. The other constituents are explained below.

The civil engineering department advisory board constitutes of about ten civil engineering practitioners representing the various branches within civil engineering and the Seattle University civil engineering faculty. The practitioners come from a pool of local alumni, employers of graduates and project sponsors. The board meets quarterly to discuss, brainstorm and provide feedback on 
program assessment, curriculum improvement and student retention. The senior design subcommittee within the civil engineering advisory board consists of four licensed civil engineering professionals and the department's design coordinator. The four external members have a good complement of technical expertise ranging from structural, water resources, geotechnical to environmental engineering. This subcommittee is very involved in the assessment process which will be discussed later in the paper.

The Project Center advisory board consists of about ten engineering professionals from civil, electrical, mechanical, computer science and software engineering, faculty representatives from each engineering discipline, and Project Center personnel. The practitioners are managers from companies, alumni, employers of graduates and project sponsors. The board meets quarterly to discuss project recruitment, assesses the student oral presentations on Projects Day, and surveys the sponsor liaisons for satisfactory completion of projects. Their contribution to the assessment, too, will be discussed later in the paper.

\section{Criterion 3 (a-k) Program Outcomes, Course Learning Outcomes}

ABET Criterion 3 requires that all engineering graduates demonstrate the following a-k program outcomes.

a) an ability to apply knowledge of mathematics, science and engineering.

b) an ability to design and conduct experiments, as well as to analyze and interpret data.

c) an ability to design a system, component or process to meet desired needs within realistic constraints.

d) an ability to work in multidisciplinary teams.

e) an ability to identify, formulate, and solve engineering problems.

f) an understanding of professional and ethical responsibility.

g) an ability to communicate effectively.

h) broad education necessary to understand the impact of engineering solutions in a global, economic, environmental, and societal context.

i) a recognition of the need for, and an ability to engage in life-long learning.

j) a knowledge of contemporary issues.

k) an ability to use the techniques, skills, and modern engineering tools necessary for engineering practice.

The civil engineering faculty developed a list of course learning outcomes for the senior design sequence. Each of the course learning outcomes was mapped to one or more $\mathrm{a}-\mathrm{k}$ program outcomes. The course learning outcomes and the corresponding program outcomes for each, indicated within parentheses, are listed below.

1. Identify the engineering problem that needs to be solved (e).

2. Describe the project to peers and faculty through oral presentations during the project development phase (g). 
3. Develop design alternatives and evaluate them using a decision matrix, as appropriate for the project (a, c, e, f, h, j, k)

4. Apply scientific and engineering principles to the assigned project (a, c, e, k).

5. Optimize the engineering design based on client expectations, design constraints, and constructability (a, c, e, f, h, j, k).

6. Demonstrate effective written communication skills through the development of a written proposal, progress reports and final project report evaluated by faculty, liaison(s) and Civil Engineering advisory board (g).

7. Demonstrate effective oral communication skills through presentations to the class, civil engineering professional society, and sponsoring agency with effectiveness being evaluated by peers, faculty and professional engineers (g).

8. Be able to function effectively on a team, with effectiveness being determined by peer ratings, self-assessment and direct observation (d, f).

9. Demonstrate professionalism through the ability to meet deadlines, manage the project team and budget, prepare and revise project schedules, conduct project meetings, as evaluated by peers and faculty (d, f, g, k).

\section{Assessment Tools}

Table 1 lists the assessment tools used in the design sequence throughout the year, the criterion 3 (a-k) program outcomes and department's course learning outcomes that particular tool assesses, and the constituents involved in that assessment process. The table shows that each assessment tool satisfies multiple a-k program outcomes and course learning outcomes. A discussion of each assessment tool follows.

\section{a) Written Proposal and Final Report}

As mentioned previously, the design teams prepare a written proposal in the fall quarter and a final report in the end of spring quarter. The fall quarter proposal covers the project background, problem statement, project objective, scope of work, plan of implementation (task break down and deliverables at the completion of each task, if applicable), project schedule, budget, references and bibliography and team member resumes. The spring quarter final report consists of project background, team's solution to the problem, external constraints controlling the design (such as political, social, economic and ethical issues), relevant calculations, engineering drawings (whenever applicable), conclusions and recommendations to the sponsors. Faculty from the Seattle University Engineering and English departments developed a set of writing guidelines to assist the students in preparing these documents ${ }^{1}$.

The proposal is reviewed multiple times by various constituents. Figure 1 shows the multiple feedback loop in the proposal assessment process at various stages of the document. In the early stages of the proposal, the document is reviewed and critiqued by the design coordinator, faculty advisor, and a technical writer from outside the engineering department. During the mid stages of the proposal, in 
addition to the above reviewers, sponsor liaisons review the document mainly to ensure that the team has a good understanding of the project, the scope, approach and the project deliverables. When the proposal is close to completion, the senior design subcommittee of the civil engineering advisory board (described earlier) joins the assessment team. The subcommittee reviews it for professional competency, thoroughness of the approach and pinpoints deficiencies in the document. Feedback from all constituents is given to the teams at various stages and the teams address these comments before finalizing the proposal.

Table 1. Assessment Tool, Criterion 3 (a-k) Program Outcomes Assessed, Course Learning Outcomes met, and Constituents Involved

\begin{tabular}{|l|l|l|l|}
\hline Assessment Tool & \multicolumn{1}{|c|}{$\begin{array}{c}\text { Criterion 3 } \\
(\mathrm{a}-\mathrm{k})\end{array}$} & $\begin{array}{c}\text { Course Learning } \\
\text { Outcomes }\end{array}$ & \multicolumn{1}{|c|}{ Constituents Involved } \\
\hline $\begin{array}{l}\text { Written Proposal } \\
\text { \& Final Report } \\
\mathrm{c}, \mathrm{e}, \mathrm{f}, \mathrm{g}, \mathrm{h}, \mathrm{k},\end{array}$ & $1,3,4,5,6$ & $\begin{array}{l}\text { Faculty, Academic Staff, } \\
\text { Sponsor Liaisons, Senior } \\
\text { Design Subcommittee }\end{array}$ \\
\hline Oral Presentations & $\mathrm{e}, \mathrm{g}$ & $2,3,4,5,7$ & $\begin{array}{l}\text { Faculty, Academic Staff, } \\
\text { Students, Sponsor Liaisons, } \\
\text { Project Center Staff and the } \\
\text { Advisory Board, Panel of } \\
\text { Professional Engineers }\end{array}$ \\
\hline Team Evaluations & $\mathrm{d}, \mathrm{g}$ & 8,9 & $\begin{array}{l}\text { Faculty Advisors, Students } \\
\text { Sponsor Surveys }\end{array}$ \\
$\mathrm{c}, \mathrm{f}, \mathrm{g}, \mathrm{k}$ & $1,3,4,5,6,7$, & $\begin{array}{l}\text { Sponsor Liaisons, Project } \\
\text { Center Staff and the } \\
\text { Advisory Board, Faculty, } \\
\text { Academic Staff }\end{array}$ \\
\hline $\begin{array}{l}\text { Comprehensive } \\
\text { Exam }\end{array}$ & $\mathrm{a}, \mathrm{e}, \mathrm{f}$ & 4 & Faculty, Academic Staff \\
\hline $\begin{array}{l}\text { Senior Synthesis } \\
\text { Paper }\end{array}$ & $\mathrm{f}, \mathrm{h}, \mathrm{i}, \mathrm{j}$ & - & Faculty \\
\hline
\end{tabular}

${ }^{a}$ this outcome is applicable to selected projects only.

For most students this is the first time that they have had to write multiple drafts of a single technical document. The dynamic and cyclic nature of receiving multiple feed back from different constituents, sorting out the - sometimes contradictory - comments and addressing them is an eye opening experience. In general, the author has observed that the teams take the external constituent's comments more seriously than those of internal constituents.

A similar assessment system is in place for the final report. The only difference being that a technical writer does not participate in the assessment process of the report. The advantage of having a technical writer in the assessment loop is that 
the faculty advisor and the course instructor are usually too close to the project and therefore, when reviewing documents, tend to fill in (their own minds) the missing details. Whereas, in this case the technical writer had a technical background but was not familiar with the project details. Therefore, the technical writer's comments, improved the clarity of the document, in addition to improving grammar, writing style and formatting of the document.

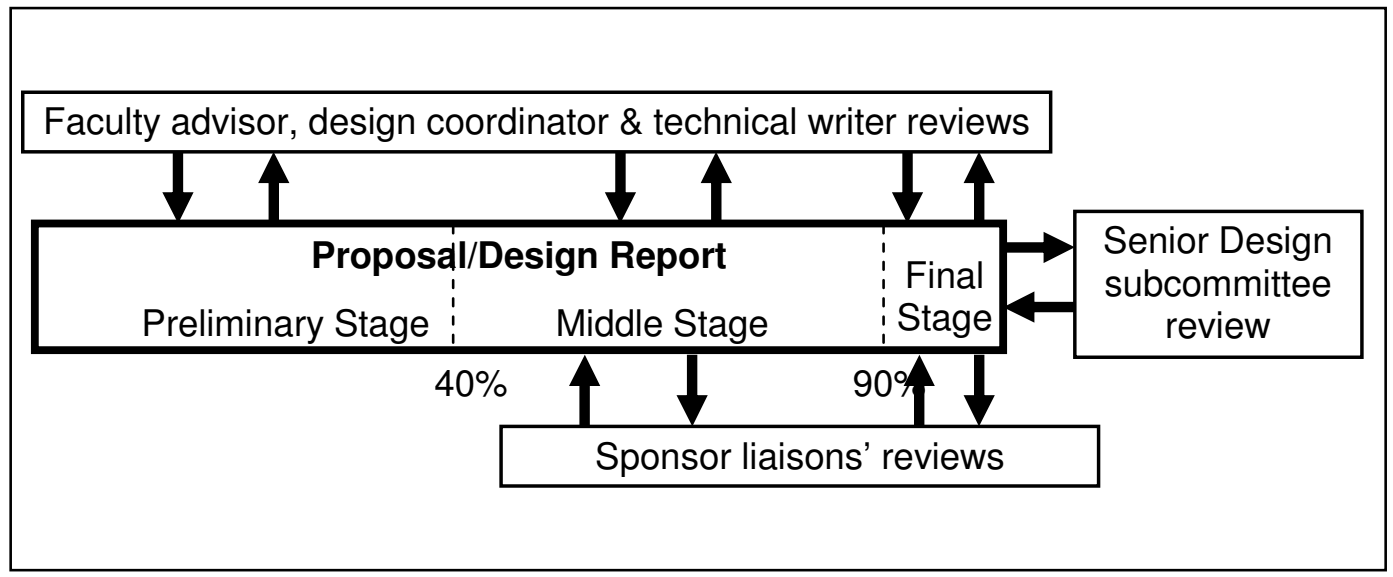

Figure 1. Assessment and Feedback Loop for Project Documents

The feedback loop shown in Figure 1 improved the quality of the proposal. But the department was interested in quantifying the improvement so that performance of different projects could be compared within a year and, class performance could be compared from year to year. A scoring rubric, part of which is shown in Figure 2, was developed by the Engineering and English department faculty and is periodically updated with input from the senior design subcommittee and civil engineering faculty. The reviewers also assess the written document holistically on a scale of 1 through 6 where examples are provided for each scoring level ${ }^{1}$. The subcommittee members use these rubrics when reviewing the final drafts of the documents. A panel of civil engineering faculty uses these same rubrics when grading the final version of the proposals and reports. The senior design subcommittee's scores of the final draft are compared with that of the scores of the faculty panel and trends in scores are discussed at advisory board meetings. A sample of faculty panel and senior design subcommittee scores for six projects from 2005-2006 proposals and final reports is shown in Table 2.

Criterion 3 program outcomes c (design), e (problem solving), $\mathrm{f}$ (professional and ethical responsibility), g (communication), h (global awareness), and k (use of modern tools) are assessed through the written proposals and final reports. In selected projects program outcome b(design of experiments) is assessed. 
Please rank the proposal/report on a scale of 1 through $6-6$ being very strong and 1 being very weak.

First Impression--Document Design: [Follows Project Center manuscript guidelines for heading, page format, etc.; has cover letter of transmittal, title page, TOC (and list of figures/tables), Introduction, Scope of Work, Plan of Implementation; headings in TOC match headings in body; figures and tables are correctly labeled and referenced in text]

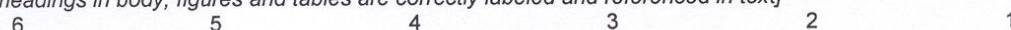

Letter of Transmittal: [Makes good first impression; summarizes problem and team's design approach; creates confidence in team's professionalism]

$$
4
$$

Executive Summary/Abstract ${ }^{\mathrm{a}}$ : [Ability to synthesize the project background, purpose, design approach and along with conclusions and recommendations; should be self-contained; ie. Reader should be able to understand the main features of the project by reading this part.]
$5 \quad 4$
3

Introduction: [Opens with summary of project's purpose; states problem clearly; shows understanding of the problem from a technical standpoint; specifies sponsor-provided parameters/criteria that must be met; shows problem's significance to company; provides needed background] 5

Scope of Work (specification of work to be accomplished and deliverables) ${ }^{\mathrm{b}}$ : [Clearly shows what the team will do; often breaks the work into stages or subgoals; deliverables clearly specified] 6 5

Scope of Work (alternative solutions/evaluation) ${ }^{\mathrm{b}}:$ [Shows alternative approaches to solving problem; outlines strengths and weaknesses of each approach; specifies criteria for choosing best design approach; convinces reader that criteria are appropriate; applies criteria clearly using decision matrix. (If alternative solutions are not applicable, proposal explains and justifies their absence--e.g., sponsoring company specified design approach)]

6 . 5 sponsoring company specified design approach)\}

3

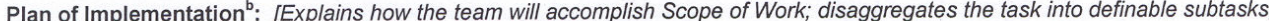
explains timeline and division of labor; when appropriate describes methods to be employed; convinces reader of team's

professionalism and dependability$$
5
$$

3

Design Methodology (alternative solutions/evaluation) ${ }^{\mathrm{a}}$ : [this section is specific to the project; it could cover the following, but is not restricted to: design alternatives considered; specifies criteria for choosing best design; sampling approach; applies decision matrix, when appropriate.
6
5
4
3
1

Conclusions and Recommendations ${ }^{\mathrm{a}}$ : [Makes conclusions based on the work carried out; comes up with thoughtful recommendations for future work.]

4

Reference and Bibliography: [All references used in the project and in the preparation of the report are listed; the format follows a consistent pattern; references include author, name of publisher, year and volume whenever appropriate; personal communications and websites and properly referenced; reader can track down all references, if needed]

5

3

2

1

Reader Friendliness: [Reader energy stays focused on content rather than structure; clear organization; parts in right place; parts clearly related to whole; follows old/new contract; sentences are grammatically correct and coherent; absence of noise; reader seldom gets lost]

$\begin{array}{llllll}6 & 5 & 4 & 3 & 2 & 1\end{array}$

Evidence of Technical Mastery: [Quality and depth of work; adequacy of design process; good understanding of technical issues;

evidence of both creative and analytical thought; professional thoroughness]

6

3

Substantial Effort: [Evidence that the team has put in substantial effort in completing the project]

5

4

Figure 2. Proposal and Final Report Scoring Rubric ( ${ }^{\mathrm{a}}$ criterion for final report; criterion for proposal)

\section{b) Oral Presentations}

Students make 15 minute oral presentations to the class using audio-visual aids several times during the year. Figure 3 shows the multiple feedback loop for the oral presentations. Each quarter every team member is required to make at least one presentation. The presentations are assessed by department faculty for technical content, use of effective visual presentations, delivery and style. The students assess the presentation for clarity, technical mastery, and educational value to them. Written comments from faculty and students are compiled 
separately and shared with the teams and their faculty advisors. These comments enable speakers to improve their oral communication skills. The audience also comments on technical clarifications needed to understand the project better, any annoying mannerisms and how the team could improve their visuals for future presentations.

Table 2. Comparison of Scores (on a scale of $1-6$ ) of the Senior Design Subcommittee vs. Faculty Panel for 2005-2006 Projects

\begin{tabular}{|c|c|c|c|c|}
\hline $\begin{array}{c}\text { Project } \\
\text { Number }\end{array}$ & \multicolumn{2}{|c|}{ Senior Design Subcommittee } & \multicolumn{2}{c|}{ Faculty Panel } \\
\hline & Proposal & Report & Proposal & Report \\
\hline 1 & 5.3 & 5.3 & 4.7 & 4.8 \\
\hline 2 & 4.9 & 4.8 & 5.2 & 5.4 \\
\hline 3 & 4.9 & 5.1 & 4.4 & 5.0 \\
\hline 4 & 5.0 & 5.2 & 5.1 & 5.4 \\
\hline 5 & 5.3 & 4.6 & 4.5 & 4.8 \\
\hline 6 & 5.6 & 5.8 & 5.7 & 5.5 \\
\hline
\end{tabular}

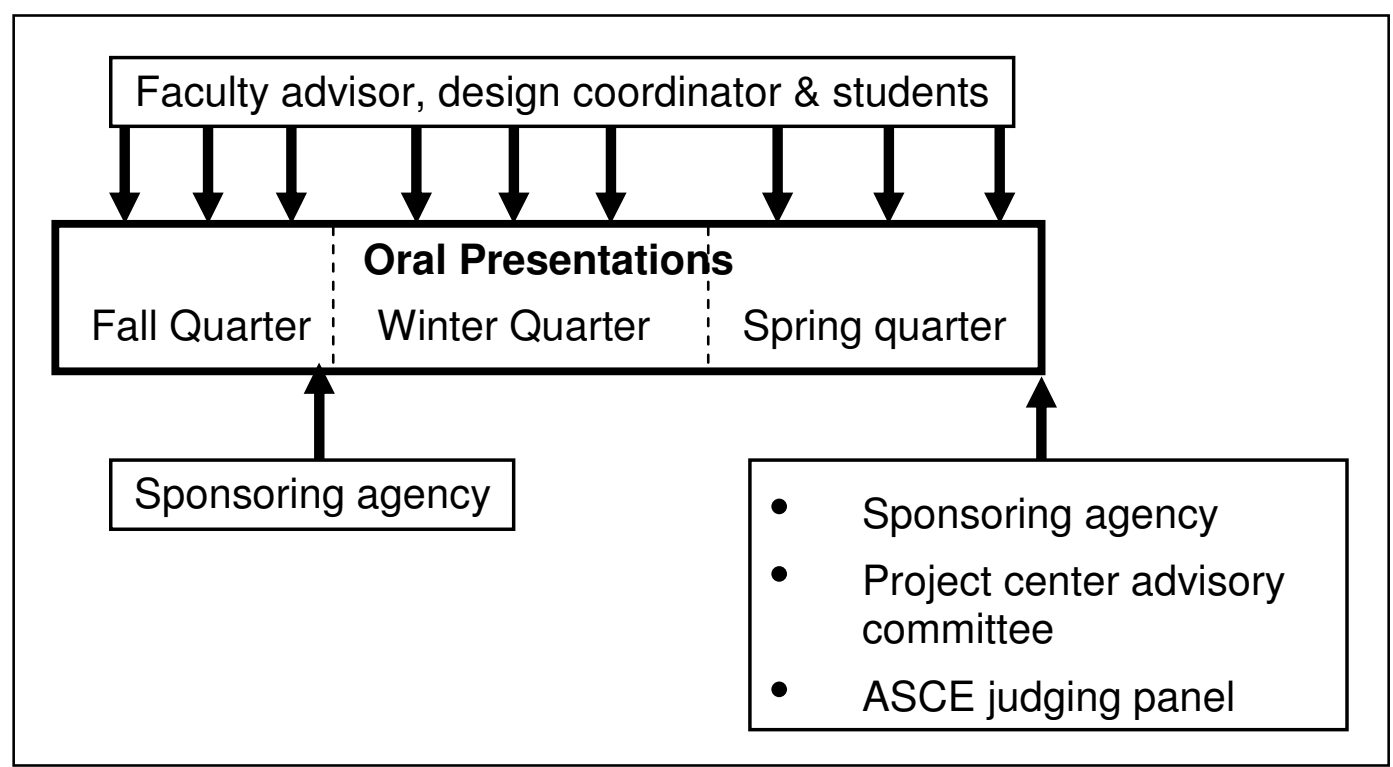

Figure 3. Assessment and Feedback Loop for Oral Presentations

In order to quantitatively compare the presentations within a year and from year to year, a scoring rubric was developed. Figure 4 shows the evaluation matrix used at the end of winter and spring quarters. Because the duration of these presentations are short, end of quarter presentations are called 'complete presentations' and cover a summary of the project background, goal, and what the team has accomplished so far. Mid quarter presentations are called 'progress presentations' where teams present work done since previous presentation. This enables the teams to present finer details of their project such as a particular 
design concept, modeling technique or experimental details, which otherwise will not be possible in a 'complete presentation'. Separate scoring rubrics are available for progress presentations (to be used in winter and spring) and proposal presentations (to be used in fall) and could be obtained by contacting the author.

COMPLETE PRESENTATION - EVALUATION MATRIX

Evaluator:

Date:

Team Number \& Project Title:

RANK EACH ITEM ON A SCALE OF 1(POOR) THROUGH 5 (EXCELLENT)

\section{TEAM SCORE}

a) Technical Content

1) Effective introduction/background to understand the presentation

2) Project issues, tasks \& elements described clearly and given appropriate emphasis

3) Technical merit of project approach/methodology

4) Technical merit and thoroughness of design/research results

5) Strong conclusions/recommendations/summary \& presented clearly

6) Clarity of presentation and ability to educate audience

7) Logical arrangement of material and smooth transition between topics

8) Q \& A handled smoothly, answered appropriately

9) Bonus points

A) Total $1(\max 45)$

b) Visual Presentation

1) Use of creative and effective audiovisual features

2) Slide readability, layout and ability to hold audience interest

3) Effectiveness of slides in conveying purpose

B) Total $2(\max 15)$

c) Delivery and Style

1) Content balance between speakers and timing within allotted time

2) Transition between speakers is smooth

C) Total $2(\max 10)$

INDIVIDUAL SCORE

a) Oral Presentation

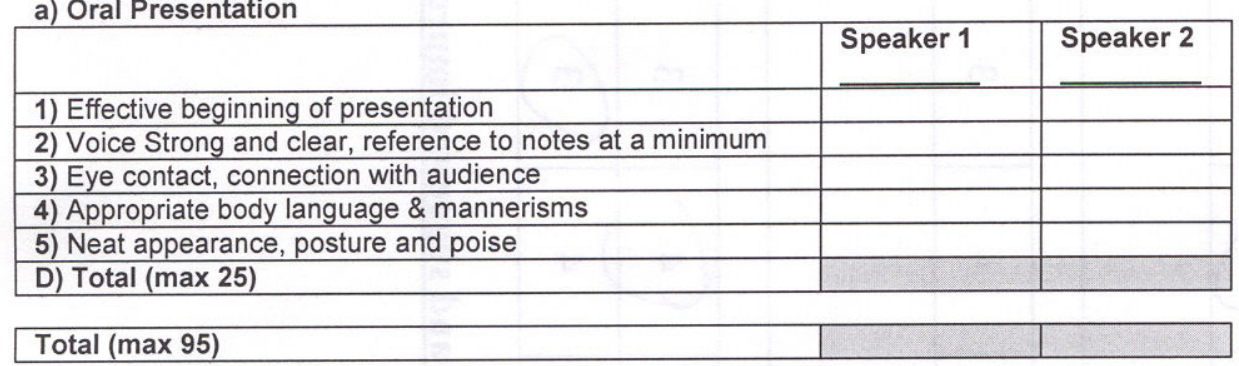

Figure 4. Oral Presentation Scoring Rubric

These scoring rubrics are shared with students at the beginning of each quarter. Clearly defining the expectations for each presentation has helped the students to know what is expected of them. These quantitative rubrics are reviewed periodically and modified by faculty as needed.

In addition to in-class presentations, teams are required, whenever possible, to make presentations at the sponsoring agency in the end of fall quarter to demonstrate their understanding of the project and their plan of implementation. 
They make a second presentation at the sponsoring agency at the end of spring quarter to present their final design, conclusions and recommendations. These are assessed via a sponsor survey which is discussed later in the paper.

In May all teams are required to participate in the Annual American Society of Civil Engineers (ASCE) Seattle Chapter Student Presentation competition. The presentations are judged by a panel of professional engineers and the top seed is invited to make the presentation at the ASCE Seattle Section May meeting which is attended by several practicing engineers.

At the end of the spring quarter the teams present again on Projects Day which is a mini-conference style event held on campus. Campus community, past, present and future project sponsors, alumni and local community attend this event. A couple of project center advisory committee members attend these presentations to assess the quality of projects and the presentations.

The presentations to the sponsors, to the ASCE panel of judges, and to the broad Projects Day audience are an intimidating but wonderful learning experience for the teams. Several graduates during informal conversations have expressed that repeatedly presenting the project to the class and the written feedback helped them build confidence in public speaking and improved their oral communication style.

Criterion 3 program outcomes e (problem solving) and g (communication) are assessed through the oral presentations.

\section{c) Team Evaluations}

At the departmental level, at the end of every quarter a confidential evaluation is completed by the team members and the faculty advisor to assess each team member's contribution towards the project. This assessment tool, shown in Figure 5, assesses each team member's contribution towards project, preparedness and participation at team meetings, and team dynamics. This tool was developed based on the work of other researchers ${ }^{2,3}$. The design coordinator summarizes the comments of faculty advisor and team members each quarter and provides written feedback to each student on their strengths and areas of improvement.

In addition to this, the Project Center carries out a bi-annual assessment through questionnaires sent out to students and faculty advisors. These assess team effectiveness, faculty advisor and sponsor involvement and interest, and facilities available to students at Seattle University to complete the project. Copies of these assessment tools can be obtained by contacting the author. 


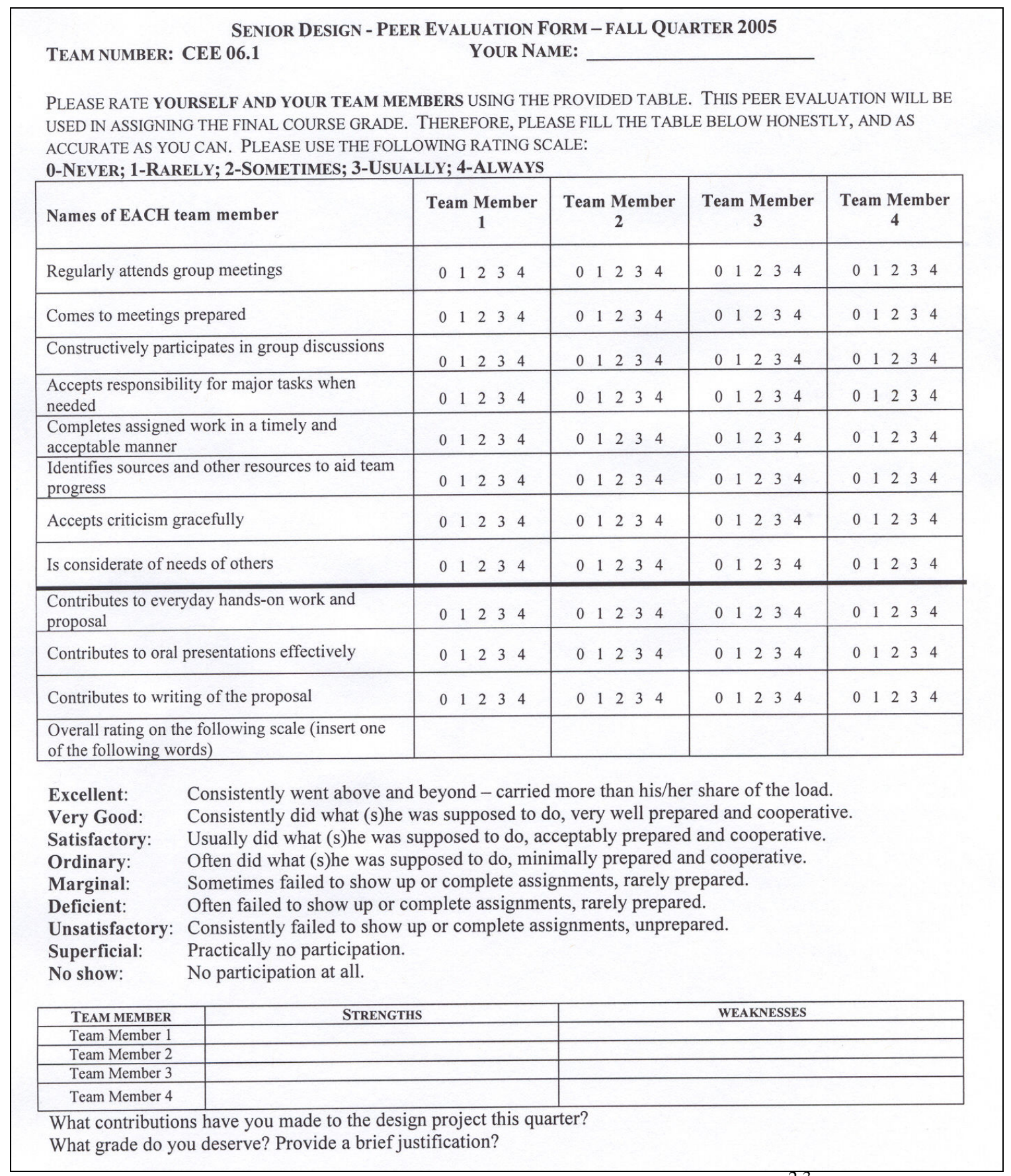

Figure 5. Evaluation Form for Assessing Team Performance (based on ${ }^{2,3}$ )

The departmental evaluations are found to be useful in early detection and intervention of team problems, identifying areas of self-improvement for students and faculty advisors. The Project Center assessments are useful in overall improvement of the program such as knowing which sponsors and types of projects are most beneficial to the program, facilities that need improvement, etc.

Criterion 3 program outcomes $\mathrm{d}$ (multidisciplinary team work), $\mathrm{g}$ (communication), are assessed through these assessment tools. 


\section{4) Sponsor Surveys}

Sponsor satisfaction is important for the overall sustainability of the capstone program. The best indication of sponsor satisfaction is their willingness to sponsor projects in subsequent years and referring other sponsors to the senior design program.

The Project Center carries out a bi-annual, web-based assessment through questionnaires sent out to liaisons ${ }^{4}$. The mid year surveys are reviewed by Project Center personnel and the departmental coordinator to identify problems or concerns, allowing time to resolve them. The end of the year survey helps to check on progress against initial goals and to see if previously identified problems have been resolved.

Criterion 3 program outcomes c (design), $\mathrm{f}$ (professional and ethical responsibility), $\mathrm{g}$ (communication), $\mathrm{k}$ (use of modern tools) are assessed through sponsor surveys.

\section{5) Comprehensive Exam}

National Council of Examiners for Engineering and Surveying's (NCEES) Fundamentals of Engineering (FE) exam has been used to assess some of the criterion 3 program outcomes ${ }^{5,6,7}$. Seattle University requires that all civil engineering graduates take the FE exam prior to graduation. But it does not require that they pass it. Not requiring the students to pass the FE exam prior to graduation poses questions on the validity of the test as an assessment tool due to lack of motivation of the students.

To overcome this, the civil engineering department has been administering a comprehensive exam in the fall and winter quarters to assess each student's fundamental knowledge of math, science and engineering, problem solving skills and knowledge of ethics. Because $20 \%$ of the student grade in fall and winter comes from these comprehensive exams, it is assumed that students would be motivated to do well. Therefore it is believed that that these comprehensive exams are a better indicator than performance in the FE exam. The added benefit of these tests is that they provide an opportunity for the student to prepare for the NCEES's FE exam in October or April. Each quarter's test is two hours long and the multiple choice format questions are purchased from ExamCafe ${ }^{8}$.

The fall quarter exam simulates the morning portion of the FE exam and covers chemistry, computers, dynamics, ethics, fluid mechanics, math, statics and mechanics of materials. The winter quarter exam simulates the afternoon portion of the subject specific FE exam. The topics covered are computers and numerical methods, environmental engineering, hydraulics and hydrology systems, legal and professional aspects, soils mechanics and foundation design, structural analysis, 
surveying and water treatment. The number of questions in each section is balanced such that students specializing in structural engineering don't have an edge over those specializing in environmental engineering. Prior to the exam, each faculty reviews and selects questions from ExamCafe in their area of expertise or in areas that they are comfortable with.

After each quarter, the faculty reviews student performance in each subject area and makes appropriate adjustment in the course curriculum. Criterion 3 program outcomes a (fundamentals), e (problem solving) and f (ethical responsibility) are assessed through the comprehensive exam.

\section{6) Senior Synthesis Paper}

Seattle University is a Jesuit college that believes in educating the whole person. Students are encouraged to develop a sense of responsibility for themselves and to their community. All civil engineering graduates are required to take 45 (quarter) credits of humanities. The university requires that students, in their senior year, synthesize their education of a whole person by reflecting on their humanities classes, courses and experience in their area of specialization, and their responsibility to the world.

To satisfy the university's senior synthesis requirement, students in senior design are required to write a paper combining the humanities, scientific, social, ethical and religious perspectives of their education. In this paper, the students examine their personal and intellectual development, their major field of study, and their future. The paper focuses on the student's comprehension of the complexity of the world and how engineering can be used to approach real-world issues and problems with humanity and sophistication.

For example, in the spring of 2006 students were asked to identify a contemporary issue (such as global warming), discuss its relevance to engineering, describe the impact of engineering solutions in a global, economic, environmental and societal context, and discuss their understanding of professional and ethical responsibility related to that issue. The students are also required to explain the recognition of the need for life-long learning and how their educational experience in college has prepared them to continue their intellectual growth throughout their career. This senior synthesis paper is assessed by faculty.

Criterion 3 program outcomes $\mathrm{f}$ (professional and ethical responsibility), h (global awareness), $\mathrm{i}$ (lifelong learning) and $\mathrm{j}$ (contemporary issues) are assessed through the senior synthesis paper.

\section{Effectiveness of the Various Assessment Tools}

The degree of effectiveness varies from one assessment tool to another. Written proposal, final report and oral presentations were highly effective assessment 
tools. Team evaluations were sometime skewed by those students who did not wish to provide honest evaluation of their peers. It is the observation of the author that students tend to protect their peers. In such situations, discussion with faculty advisor has helped to clarify team assessment issues. Sponsor surveys were effective because sponsors have an interest in developing well rounded graduates by the time they enter the work force. In addition, sponsors are also looking for a return on their investment, especially if they are planning to sponsor projects in the future. Therefore, their feedback is highly valuable to the program. Comprehensive exam has so far produced mixed results. In some cases, students whom the faculty considered academically strong have performed below their potential. This could be due to simply getting used to taking a web based exam or inadequate preparation for the exam on the part of the student. To overcome the first, the department directs the students to the Examcafe website and suggests they try the free sample problems prior to the comprehensive exam. For the latter, the department is considering having review sessions prior to the comprehensive exam. Finally, the senior synthesis paper was found to be a very effective assessment tool.

\section{Benefits of and Continuous Improvement through Assessment}

When ABET 2000 criterion was introduced a decade ago there were several educators frustrated with the assessment process. Selecting and implementing assessment tools for some of the program outcomes was challenging. But once the period of shock was gone, we realized how our programs could be improved through assessment.

The Seattle University engineering program went through a successful accreditation visit in the fall of 2005. The ABET was highly complimentary of the senior design program.

The assessment tools in place have helped us identify areas of weaknesses of the graduates as well as the program. They have aided us educate better prepared graduates with strong technical and soft skills. Bringing the diverse constituents into the assessment process has strengthened the program. In the current global market to stay competitive we have continuously reviewed the assessment tools, the process, and the results and have made appropriate changes to improve the program.

\section{Conclusions}

Project based senior design capstone experience effectively satisfies both, ABET 2000 criterion 4 (that students participate in a major design experience) and most criterion 3 (a-k) program outcomes. Seattle University's 20-year old senior design program has evolved over the years to meet many, if not all, of the criterion 3 (a-k) program outcomes. These assessment tools may not be the best but by continuously reviewing and revising them we are striving to make the 
program better. The engineering program had a successful ABET review in the fall of 2005.

\section{References}

1. Seattle University (2007). http://www.seattleu.edu/scieng/engpc/infor/ (January 5, 2007)

2. Felder R.M., Brent R. (2004). National Effective Teaching Institute Workshop, American Society of Engineering Education Annual Conference. E1-29.

3. BESTEAMS Building Engineering Student Team Effectiveness \& Management Systems, http://www.enme.umd.edu/labs/BESTEAMS/ (January 5, 2007)

4. Seattle University Engineering Project Center (2007). http://www.seattleu.edu/scieng/engpc/2006_MidYear/ (January 5, 2007)

5. Nirmalakhandan N., Daniel D., White K. (2004). Use of subject-specific FE Exam Results in Outcomes Assessment, Journal of Engineering Education, 93 (1).

6. Wicker R.B., Qunitana R., Tarquin A. (1999). Evaluation Model using Fundamentals of Engineering Examination, Journal of Professional Issues in Engineering Education and Practice, 125 (2).

7. Mazurek D.F. (1995). Consideration of FE Exam for Program Assessment, Journal of Professional Issues in Engineering Education and Practice, 121(4).

8. Exam Café - Online Practice Exams and Problems (2006). http://ppi2pass.com/ppi/ECMain (January 5, 2007) 